Aim of the study: The objective of the study was to determine the body composition (BC) changes in women with breast cancer after endocrine therapy, and the influence of aerobic training on the parameters under discussion.

Material and methods: 41 women aged 32-48 (mean \pm SD $44.1 \pm 4.4$ ) with breast cancer during endocrine therapy (ET). This was a nonrandomized, prospective trial. The following examinations were conducted in patients according to the schedule: I before the beginning of ET; II after 6 months of the ET; III after 12 months of ET and after 6-month aerobic training. Body composition was evaluated using dual X-ray absorptiometry (DEXA) with respect to free fatty mass, lean, fat and the percentage location of android and gynoid fat. The body build was evaluated with respect to body height, body weight and selected anthropometric parameters BMI and WHR

Results: During the first six months of ET without regular physical activity the following was reported: a significant increase of body weight, BMI, the amount of fatty tissue, including android fat distribution $(p<0.05)$; the lack of any significant change in the amount of gynoid fatty tissue $(p>0.05)$. At that time muscle $(p<0.05)$ and free fatty mass $(p>0.05)$ reductions were reported. After the sixmonth aerobic workout no significant body weight or BMI increase was observed. However, there was a significant reduction in WHR $(p<0.05)$, which correlated with the decrease of android fatty tissue $(p<0.05)$. The other elements evaluated in the DEXA underwent statistically insignificant changes.

Conclusions: The outcome analysis allows us to conclude that during breast cancer ET the patients are reported to have negative changes in $\mathrm{BC}$ and physique. Therefore, this patient group is advised to receive regular rehabilitation with the aim of reducing the side effects of the treatment. However, aerobic training seems to be insufficient in order to fully reduce the side effects of this form of cancer therapy.

Key words: aerobic exercise, body build, oncology, hormonal therapy.

\section{The influence of aerobic training on body composition in premenopausal women undergoing endocrine therapy for breast cancer}

\author{
Katarzyna Hojan ${ }^{1}$, Piotr Milecki ${ }^{12}$
}

${ }^{1}$ Greater Poland Cancer Centre, Poznan

2Department of Electroradiology, Poznan University of Medical Sciences

\section{Introduction}

Endocrine therapy (ET) is an integral part of oncological treatment for patients with breast cancer with oestrogen receptor expression, regardless of age and menopausal status [1]. Based on the recommendations of the St. Gallen Conference 2009 [2], which every two years sets out standards for the treatment of breast cancer, women with breast cancer before menopause and after menopause were divided into three groups - sensitive to ET, with potential sensitivity and insensitive to ET. Lowering the level of oestrogen before menopause can be achieved with ovarian ablation or suppression, and by blocking the oestrogen receptors present in the tumour cell through the application of anti-oestrogen [3]. Women may be deprived of ovarian function using an operational method (ovariectomy) or by radiation (radiation castration). In recent years, these treatments have been replaced by the use of drugs acting on the pituitary and excluding ovarian function in a reversible manner, socalled pharmacological castration [2, 4]. Tamoxifen is a standard adjuvant therapy for premenopausal women with hormone-sensitive breast cancer with indications only to use ET (patients with low risk and some patients with medium risk) [3, 4]. A meta-analysis, EBCTCG [5], demonstrated that ovarian ablation, surgical or radiation, as the sole method of adjuvant therapy significantly improves asymptomatic and overall survival for women before 50 years of age. Used in combination with tamoxifen it has comparable effects to chemotherapy (CMF) $[1,4,6]$. Studies [6, 7] on the adjuvant treatment of patients with oestrogen receptor expression have demonstrated that the combination of suppression or ablation of ovarian function in conjunction with tamoxifen is considered to be safe and as effective as chemotherapy. The use of GnRH analogues (LHRH), resulting in oestrogen deficiency, causes a number of adverse events [8] such as reduction in bone mineral density, adverse metabolic changes and disturbances in the sphere of mental functioning. Changes in body composition (BC) of women treated with blocking ovarian function appear to be similar to post-menopausal ones $[9,10]$. For women after menopause, weight gain occurs, having an unfavourable redistribution of body fat, with an increase of visceral fat and a decrease in lean body mass $[11,12]$. Long-term hypo-oestrogenaemia is one of the major factors responsible for the development of atherosclerosis and the severity of insulin resistance, hypertension and impaired glucose metabolism [11, 13, 14]. Visceral obesity promotes the release of large amounts of free fatty acids (FFA), which results in the inhibition of glucose uptake by target cells, hyperinsulinaemia and subsequent insulin resistance [15]. Insulin resistance and hyperinsulinaemia through the intensification of the synthesis of lipoproteins of very low density lipoproteins $(V L D L)$ in the liver lead to the occurrence of hyperlipidaemia char- 
acterized by proatherogenic lipid profile, increased LDL cholesterol and reduced levels of protective HDL fraction [16]. Both insulin resistance and hyperinsulinaemia contribute to the reconstruction of vessel walls, disrupting their contractility, and increasing the clotting process, which enhances the progression of atherosclerosis and leads to an increased risk of developing diseases of the cardiovascular system [17]. Systematic physical training favourably affects the cardiovascular system, both directly and indirectly by modifying and limiting the impact of other risk factors for cardiovascular disease, especially obesity, dyslipidaemia and hypertension [18-20]. The Post-Menopausal Oestrogen / Progestins Intervention Study showed that the level of physical activity was positively correlated with serum HDL-C and negatively with serum insulin and fibrinogen [21]. Published results of studies on the impact of changes associated with ET in breast cancer patients on the physical state are ambiguous. Therefore, the attempt of an objective assessment of selected components of the clinical condition in young women treated with hormone for breast cancer has been made to determine the effect of aerobic training on the test parameters.

\section{Aim of the study}

Evaluation of the impact of aerobic training on $B C$ and structure, that is, to determine the distribution and amount of body fat, lean body mass and selected anthropometric assessment of BC in women before menopause, hormonally treated for breast cancer.

\section{Material and methods}

The study included fifty-three women, but the programme was completed by forty-one at the age of 32-48 years old (mean \pm SD $44.3 \pm 4.9$ ) diagnosed with breast cancer, oncologically treated in the period from October 2007 until December 2008 at the Cancer Centre in Poznan. The study was approved by the Bioethics Committee at the Medical University in Poznan. Participation in the study was subject to obtaining voluntary conscious consent of the patient.

Criteria for inclusion in the study: age from 18 to 50 years old, regular menses until incorporation hormone, female sex, histologically confirmed breast cancer, hormonal therapy planned and continued for a minimum of one year (Goserelin 3.6 mg every 28 days, daily Tamoxifen 20 mg/day), no distant metastases, general condition good ECOG 0-1, no history of endocrine disease, rheumatic disorders, malabsorption, and other cancers and no special diet. Criteria for exclusion from the study: failure to meet inclusion criteria, patient withdrawal from the study, chemotherapy, occurrence of distant metastases and/or progression of disease resulting in the use of palliative radiation therapy, death from any cause.

\section{Methodology}

The study was not randomized, prospective study. Patients enrolled in the study underwent the following tests scheduled: 1) output test before the start of ET;

2) check-up after 6 months of ET, prior to the scheduled daily workout;
3) final examination after 12 months of follow-ET and after 6-month daily aerobic workout.

The study was conducted according to the scheme:

1) subjective examination;

2) objective examination i.e. general medical examination, taking into account the overall efficiency of the cardiorespiratory system and qualification for physical exercise. Anthropometric measurements were made:

- body height (from the surface where the test person stands to the top of the skull - with a height meter attached to medical scales);

- body weight (by using medical importance, to the nearest $10 \mathrm{~g}$, in the morning after defecation, before eating and exercise physical); on this basis the BMI (body mass index) was calculated from the formula BMI $\left[\mathrm{kg} / \mathrm{m}^{2}\right]=(\mathrm{mc})[\mathrm{kg}]$ $\left./(\mathrm{BV})^{2}\left[\mathrm{~m}^{2}\right]\right)$

- waist circumference (WC) - centimetre tape, lying horizontally and parallel to the base so that it ran through the deepest place of the lateral profile of the body - the breath holding measurement performed twice - if the two measurements differed by more than $0.4 \mathrm{~cm}$, two more measurements were performed and from the results the arithmetic mean was calculated;

- hip circumference (HC) - centimetre tape, arranged horizontally and parallel to the base so that it ran through the most protruding points back. On their basis WHR (waist hip ratio) was calculated from the formula $W H R=(W C)[m]$ $/(\mathrm{HC})[\mathrm{m}][22]$

3) densitometry: BC was determined by Dual Energy X-ray Absorptiometry (DEXA) using LUNAR PRODIGY ADVANCE Camera Software enCORE (GE Healthcare v. 10.50.086), which sets the amount of (g): lean body mass (LBM), free fatty body mass (FFBM), fat body mass (FBM) and percentage of body fat throughout the body (\% BF), including the android (\% AF) and gynoid scheme (\% GF) [23].

\section{Aerobic training}

Between 6 and 12 months of ET the patients performed daily aerobic exercise lasting from 45 to 55 minutes. To encourage the daily activities, patients were offered different forms of exercise, ensuring the attractiveness for the surveyed: fast walking or jogging on the ground or on a treadmill, cycling (stationary or recreation facilities), swimming, roller skating. The maximum heart rate during exercise was maintained at $65-70 \%$ of HRmax, calculated from the formula HRmax = 220 - age [23]. During the test breaks in training lasting up to three days a month were allowed. The verification of the training was carried out based on the diaries of physical activity of patients meetings with the doctor at least once a month.

\section{Statistical analysis}

Statistical analysis was performed using STATISTICA v.7. Quantitative data were determined by the mean, standard deviation, minimum and maximum value in the group. Two models of the results were used: longitudinal to assess changes in time, and cross to assess the relationship of variables measured at the same time points. For the evaluation of the distribution the Shapiro-Wilk test was used (compli- 
ance with the normal distribution). And the differences between the results of two studies were defined using the Wilcoxon test. To assess the relationship between the data obtained nonparametric correlation coefficient of Spearman (rs) was used. As statistically significant results were accepted with $p$ equal to or less than 0.05 .

\section{Results}

Evaluation of the test group: the average age of 44.3 years (SD 4.9) min. 32.8 years, max. 48.2 years; growth average of $164.4 \mathrm{~cm}$ (SD 5.6) min. $152 \mathrm{~cm}$, max. $172 \mathrm{~cm}$; operated breast side: right 17 (41.5\%), left 24 (58.5\%), breast conserving surgery (BCT) in 27 women (65.8\%) and total mastectomy (according to Patey) in 14 patients (34.1\%); degrees of clinical advancement $\mathrm{T}_{1}, \mathrm{~N}_{0}, \mathrm{M}_{0}-14$ (34.1\%) women, $\mathrm{T}_{1}, \mathrm{~N}_{1}, \mathrm{M}_{0}$ 20 (48.8\%) patients, $\mathrm{T}_{2}, \mathrm{~N}_{1}, \mathrm{M}_{0}-7$ (17\%) patients; receptors ER (+) in 41 patients (100\%).

Hormone therapy used for breast cancer in premenopausal women studied resulted in a change in BC (Table 1). Within 6 months of ET with no regular physical activity a statistically significant increase in body weight was found $(p=0.000011), \mathrm{BMI}(p=0.000013), \mathrm{WC}(p=0.00000)$ and WHR $(p=0.000001)$.

The analysis of changes in BC (Table 2) showed statistically significant changes, which related to decline of muscle tissue - LBM $(p=0.00614)$, increase of body fat FBM $(p=0.00708)$, including the android distribution $(p=0.00000)$. Under the influence of hormonal blockade a decrease in FFBM $(p=0.051)$ and an increase of body fat with gynoid distribution were also found ( $p=0.57$ ), but they were not statistically significant.

After 6 months of daily aerobic exercise in the study group of women studies following changes in BC were observed: significant reduction in WC $(p=0.012134)$ and WHR ( $p=0.00308)$, negligible weight loss $(p=0.43)$, BMI $(p=0.17)$ and waist circumference $(p=0.11)$. The changes observed in this study were confirmed by densitometric evaluation of BC. An increase in quantity of muscle tissue - LBM $(p=0.45)$, decrease in FFBM $(p=0.34)$ and fat percentage $-\% B F(p=0.15)$ were observed, but they were not statistically significant. The only statistically significant change found in DEXA analysis under the influence of aerobic

Table 1. Results of the anthropometric measurements and BMI and WHR indicators in different periods of the research

\begin{tabular}{|lccc} 
Mean \pm SD Min. - Max. & Before the endocrine therapy & After 6 months of observation & After 12 months of observation \\
\hline Body weight $[\mathrm{kg}]$ & $60.08 \pm 6.98$ & $65.19 \pm 11.01$ & $47-94$ \\
& $49-82$ & $24.2 \pm 4.17$ & $64.89 \pm 10.51$ \\
$48-92$
\end{tabular}

SD - standard deviation; Min. - Max. - maximal value - minimal value; BMI - body mass index; WC - waist circumference; HC - hip circumference; WHR - waist-hip ratio

Table 2. Results of the body composition in different periods of the research

\begin{tabular}{|c|c|c|c|}
\hline Mean \pm SD Min. - Max. & Before the endocrine therapy & After 6 months of observation & After 12 months of observation \\
\hline FFBM [g] & $\begin{array}{c}2508.1 \pm 320.4 \\
1938-3135\end{array}$ & $\begin{array}{c}2419.3 \pm 341.3 \\
1756-3220\end{array}$ & $\begin{array}{c}2395.8 \pm 320.7 \\
1925-3025\end{array}$ \\
\hline LBM [g] & $\begin{array}{c}37391.5 \pm 5211.6 \\
22687-49468\end{array}$ & $\begin{array}{c}36139.9 \pm 5206.5 \\
21287-49445\end{array}$ & $\begin{array}{c}36532.2 \pm 5304.8 \\
21187-48930\end{array}$ \\
\hline $\mathrm{FMB}[\mathrm{g}]$ & $\begin{array}{c}21058.7 \pm 7152.1 \\
9045-37788\end{array}$ & $\begin{array}{c}24792.8 \pm 9767.6 \\
10829-49561\end{array}$ & $\begin{array}{c}25624 \pm 9841.2 \\
11933-51817\end{array}$ \\
\hline $\mathrm{BF}[\%]$ & $\begin{array}{l}33.7 \pm 6.5 \\
22.7-44.3\end{array}$ & $\begin{array}{l}37.8 \pm 7.8 \\
24.3-53.7\end{array}$ & $\begin{array}{l}37.4 \pm 7.7 \\
24.8-49.7\end{array}$ \\
\hline GF [\%] & $\begin{array}{l}40.8 \pm 6.1 \\
27.3-52.4\end{array}$ & $\begin{array}{l}42.2 \pm 7.6 \\
22.1-55.2\end{array}$ & $\begin{array}{l}43.7 \pm 6.4 \\
29.7-56.8\end{array}$ \\
\hline $\operatorname{AF}[\%]$ & $\begin{array}{l}34.2 \pm 8.7 \\
15.8-48.4\end{array}$ & $\begin{array}{l}41.3 \pm 10.2 \\
16.2-59.2\end{array}$ & $\begin{array}{l}39.9 \pm 9.8 \\
16.6-53.3\end{array}$ \\
\hline
\end{tabular}

SD - standard deviation; Min. - Max. - maximal value - minimal value; FFBM - free fat body mass; LBM - lean body mass; FBM - fat body mass; $\%$ BF - \% body fat; \% AF - \% android fat; \% GF - \% gynoid fat 
exercise was the reduction in the percentage of fat content with android distribution ( $p=0.00033)$. The upward trend of the percentage of fat with gynoid distribution still persisted $(p=0.07)$.

The analysis of correlation between selected parameters of structure and composition of the body before the start of ET showed a statistically significant correlation $(p<0.05)$ for $\% \mathrm{BF}$ and $\mathrm{BMI}, \mathrm{WHR}$, \% fat content with android distribution. FFBM increased with increasing BMI, WHR. With the increase in LBM a reduction in the percentage of body fat including android distribution was observed - the relationship was not statistically significant.

It has been found out that after 6 months of ET the correlation between the \% BF and FFBM, BMI and WHR were not subjected to significant deviations in relation to output research. However, a statistically significant correlation between FFBM and LBM was found. After 6 months of aerobic training in patients in the $12^{\text {th }}$ month of observation there were significant relationships between the selected parameters estimating the structure and composition of the body. Statistically significant relationships were similar to those before the start of ET. It was also found that with the increase in WHR an increase in LBM was observed (which was not apparent in previous results). A summary of statistical evaluation of correlation between the assessed parameters is shown in Table 3.

\section{Discussion}

Hormone therapy is used in $60-70 \%$ of patients with breast cancer [1]. In the oncological treatment the therapeutic success is measured by 5-year survival and clinical studies [4-7] have proved the efficacy of this form of therapy for breast cancer. The study of pre-menopausal women treated with hormone shows that within six months of treatment there were significant increases in body weight and BMI, and the sex typical gynoid construction changed into android (i.e. with an increase in fat around the abdomen and chest). Similar changes in body composition were observed in the research of Nadel et al. [13] on a population of 2081 peri- and postmenopausal women, where it was found that obesity was present in $39 \%$ of women from rural areas and $21 \%$ of women from the city. The authors studying the effect of obesity on treatment and prognosis in malignant tumours stress [24-26] that it may be an important predictor of poor survival, independent of other prognostic factors. Petrelli et al. [27] found that high $\mathrm{BMI}$ is a poor prognostic factor, and the relative risk of death in patients with high BMI (more than $40 \mathrm{~kg} / \mathrm{m}^{2}$ ) was more than three times higher than in patients with low BMI (18.5-20.5 kg/m²). Also, Daling et al. [28] found in younger women a significant relationship between high $\mathrm{BMI}$ and poorer prognosis (increased mortality). It was found [29] that the relationship between sugar and fat disturbances and tumour progression is caused by hyperinsulinaemia as cell insulin resistance. Obesity and overweight are the cause of diseases of the cardiovascular, respiratory, nervous and musculoskeletal systems [17, 19]. The HOPE study (Hart Outcomes Prevention Evaluation) [18] showed that increased WC increases the risk of cardiovascular death by $24 \%$, myocardial infarction by $20 \%$ and mortality by $32 \%$. Also, Jansen et al. in the NHANES III study confirmed that the best measure of the risk of cardiovascular diseases is the WC [19]. An important place in the complex pathogenesis of the metabolic syndrome is abdominal obesity and insulin resistance. The accumulation of fat in the trunk is related, inter alia, to increased activity of the sympathetic nervous system, and the role of physical exercise is to stimulate the parasympathetic antagonist system [20]. One of the important so-

Table 3. Correlation between selected parameters of body building and composition in the different periods of the research

\begin{tabular}{|c|c|c|c|c|c|}
\hline & $\% A F$ & LBM & FFBM & BMI & WHR \\
\hline \multicolumn{6}{|c|}{ Before endocrine therapy } \\
\hline $\begin{array}{l}\text { BF [\%] } \\
\text { AF [\%] } \\
\text { LBM } \\
\text { FFBM } \\
\text { BMI }\end{array}$ & $\begin{array}{c}p=0.000 \\
-\end{array}$ & $\begin{aligned} p= & 0.181 \\
p= & 0.120 \\
& -\end{aligned}$ & $\begin{array}{c}p=0.014 \\
p=0.038 \\
p=0.126 \\
-\end{array}$ & $\begin{array}{c}p=0.000 \\
p=0.000 \\
p=0.345 \\
p=0.013 \\
-\end{array}$ & $\begin{array}{l}p=0.000 \\
p=0.004 \\
p=0.489 \\
p=0.004 \\
p=0.000\end{array}$ \\
\hline \multicolumn{6}{|c|}{ After 6 months of endocrine therapy without regular physical activity } \\
\hline $\begin{array}{l}\text { BF [\%] } \\
\text { AF [\%] } \\
\text { LBM } \\
\text { FFBM } \\
\text { BMI }\end{array}$ & $p=0.000$ & $\begin{array}{l}p=0.766 \\
p=0.965\end{array}$ & $\begin{array}{l}p=0.001 \\
p=0.017 \\
p=0.000\end{array}$ & $\begin{array}{l}p=0.000 \\
p=0.000 \\
p=0.454 \\
p=0.003\end{array}$ & $\begin{array}{l}p=0.000 \\
p=0.000 \\
p=0.168 \\
p=0.024 \\
p=0.000\end{array}$ \\
\hline \multicolumn{6}{|c|}{ After 6 months of aerobic training and 12 months of endocrine therapy } \\
\hline $\begin{array}{l}\text { BF [\%] } \\
\text { AF [\%] } \\
\text { LBM } \\
\text { FFBM } \\
\text { BMI }\end{array}$ & $p=0.000$ & $\begin{array}{l}p=0.894 \\
p=0.821\end{array}$ & $\begin{array}{l}p=0.002 \\
p=0.022 \\
p=0.000\end{array}$ & $\begin{array}{l}p=0.000 \\
p=0.000 \\
p=0.761 \\
p=0.016\end{array}$ & $\begin{array}{l}p=0.003 \\
p=0.000 \\
p=0.048 \\
p=0.012 \\
p=0.000\end{array}$ \\
\hline
\end{tabular}

Statistically significant correlations are in bold.

FFBM - free fat body mass; LBM - lean body mass; \% BF - \% body fat; \% AF - \% android fat; \% GF - \% gynoid fat 
lutions to reduce obesity and related adverse effects is to seek appropriate forms of physical activity to reduce negative changes in the body in the course of the disease. The use of improving exercises in women treated for breast cancer is rarely a problem considered in oncological treatment. Rehabilitation studies conducted according to "evidence based medicine" allow you to select curative exercises and a suitable form of treatment for patients taking the consequences of oncological treatment on the body into account. Aerobic training in patients with breast cancer before menopause applied in the present study resulted in a significant reduction in body weight and BMI. Changes under the influence of the effort involved the area of the abdomen (reduction of WC, WHR, and \% fat android). Similar changes in the construction were observed by Irving et al. [30] in women with metabolic syndrome in peri- and postmenopausal age (average age $51 \pm 9$ ). After 16 weeks of intense aerobic training they reported a significant reduction in WC and fat in the abdominal area [30]. Slentz et al. [31] obtained similar results also in patients (men and women) with metabolic syndrome. The results presented in the work of Ohkawara et al. [32] are analogous to changes in the present study in women with cancer. The applied training of a magnitude 10 MET $\times$ h / w (brisk walking, light running, stationary cycling) [32] resulted in a significant reduction in visceral body fat. In a study of women with breast cancer, cardio workout, despite the use of different forms of exercise, did not cause a significant recovery of muscle tissue lost in the first six months of ET with no regular physical activity. Velthuis et al. [33] found a reduction in fat tissue and its percentage in the option of total body in DEXA in postmenopausal women, as in the present study of cancer patients; however, they also observed a significant increase in muscle mass, which may result from the long period of aerobic training (12 months training), compared with a group of women with cancer (6 months). In young women treated with hormonal cancer, despite their regular physical activity, they observed a tendency to a decrease in the amount of LBM. This confirms the observation that the basic metabolic rate is related to the amount of LBM in women [12], as in the study of De Lorenzo et al. [34], where the LBM in patients with metabolic syndrome showed lower values than in healthy persons. Therefore, it seems that the difficulty in reducing the changes in the structure and composition of the body resulting from hormonal treatment of breast cancer before menopause may result from abnormalities similar to changes in metabolic syndrome. For this reason, in this group of patients regular improvement should be conducted to reduce the side effects of this form of oncological treatment. Application of aerobic training in the study caused a reduction in body weight and waist circumference, but it WC to fully offset the impact of ET on $\mathrm{BC}$ of patients.

\section{References}

1. Niwińska A, Litwiniuk M. Hormonoterapia uzupełniająca raka piersi. Wspolczesna Onkol 2007; 11: 82-8.

2. Goldhirsch A, Ingle JN, Gelber RD, et al. Thresholds for therapies: highlights of the St. Gallen International Expert Consensus on the Primary Therapy of Early Breast Cancer 2009. Ann Oncol 2009; 20: 1319-29.
3. Puhalla S, Brufsky A, Davidson N. Adjuvant endocrine therapy for premenopausal women with breast cancer. Breast 2009; 18 Supl 3: 122-30.

4. Early Breast Cancer Trialists' Collaborative Group. Effects of chemotherapy and hormonal therapy for early breast cancer on recurrence and 15-year survival: An overview of the randomised trials. Lancet 2005; 365: 1687-17.

5. Cuzick J, Ambroisine L, Davidson N, et al. Use of luteinising-hormonereleasing hormone agonists as adjuvant treatment in premenopausal patients with hormone-receptor-positive breast cancer: a meta-analysis of individual patient data from randomised adjuvant trials. Lancet 2007; 369: 1711-23

6. Jakesz R, Hausmaninger H, Kubista E, et al. Randomized adjuvant trial of tamoxifen and goserelin versus cyclophosphamide, methotrexate and fluorouracil: Evidence for the superiority of treatment with endocrine blockade in premenopausal patients with hormone-responsive breast cancer - Austrian Breast and Colorectal Cancer Study Group Trial 5. J Clin Oncol 2002; 20: 4621-7.

7. Goel S, Goel S, Sharma R, et al. LHRH agonists for adjuvant therapy of early breast cancer in premenopausal women. Cochrane Database Syst Rev 2009; 7: CD004562.

8. Angelopoulos N, Barbounis V, Livadas S, et al. Effects of estrogen deprivation due to breast cancer treatment. Endocr Relat Cancer 2004; 11: 523-35.

9. Thomson CA, Thompson PA, Wright-Bea J, et al. Metabolic syndrome and elevated C-reactive protein in breast cancer survivors on adjuvant hormone therapy. Womens Health (Larchmt) 2009; 18: 2041-7.

10. Biglia N, Moggio G, Peano E. Effects of surgical and adjuvant therapies for breast cancer on sexuality, cognitive functions, and body weight. J Sex Med 2010; 7: 1891-900.

11. Baranowski W. Przemiany hormonalne wieku menopauzalnego. In: Diagnostyka i terapia wieku menopauzalnego. Pertyński T (ed.). Urban \& Partner, Wrocław 2004; 1-10.

12. Wajchenberg BL. Subcutaneous and visceral adipose tissue: their relation to the metabolic syndrome. Endocr Rev 2000; 21: 697-738.

13. Nadel I, Cypryk K, Pertyński T, et al. Występowanie schorzeń zespołu metabolicznego u kobiet $w$ wieku pomenopauzalnym $w$ regionie tódzkim. Pol Arch Med Wewn 2002; 106: 823-8.

14. World Health Organization Research on the menopause in the 1990s. Report of a WHO Scientific Group. World Health Organ. Technical Report Series, Geneva 1996; 866: 1-107.

15. Debing E, Peeters E, Duquet W, et al. Endogenous sex hormone levels in postmenopausal women undergoing carotid artery endarterectomy. Eur J Endocrinol 2007; 156: 687-93.

16. Murdoch SJ, Carr MC, Hokanson JE, et al. PLTP activity in premenopausal women. Relationship with lipoprotein lipase, HDL, LDL, body fat, and insulin resistance. J Lipid Res 2000; 41: 237-44.

17. Czech A, Bernas M, Tatoń J. Sercowo-naczyniowe objawy otyłości. Endokr Otyłość 2007; 3: 85-94.

18. The World Health Report 2002. Reducing Risks, Promoting Heath Life. Geneva 2002.

19. Pupek-Musialik D, Bogdański P. Otyłość i zespół metaboliczny. Od teorii do praktyki. Via Medica, Gdańsk 2007; 37-45.

20. Murawska-Ciałowicz E, Zatoń M. Znaczenie aktywności ruchowej dla zdrowia. Wyd. AWF, Wrocław 2005.

21.Greendale GA, Bodin-Dunn L, Ingles S, et al. Leisure, home, and occupational physical activity and cardiovascular risk factors in postmenopausal women: the Post-menopausal Estrogen/Progestins Intervention (PEPI) study. Arch Intern Med 1996; 156: 418-24.

22. Drozdowski Z. Wskazówki do ćwiczeń antropometrycznych w zakresie studiów wychowania fizycznego. AWF w Poznaniu, Poznań 2002.

23. Kelly TL, Berger N, Richardson TL. DXA body composition: theory and practice. Appl Radiat Isot 1998; 49: 511-3.

24. Calle EE, Thun MJ, Petrelli JM, et al. Body-mass index and mortality in a prospective cohort of U.S. adults. N Engl J Med 1999; 341: 1097-105.

25. Rodriques C, Calle EE, Fakhrabadi-Shokoohi D, et al. Body mass index, height, and the risk of ovarian cancer mortality in a prospective cohort of postmenopausal women. Cancer Epidemiol Biomarkers Prev 2002; 11: 822-8.

26. Hebert JR, Augustine A, Barone J, et al. Weight, height and body mass index in the prognosis of breast cancer: early results of a prospective study. Int J Cancer 1988; 42: 315-21. 
27. Petrelli JM, Calle EE, Rodriguez C, et al. Body mass index, height, and postmenopausal breast cancer mortality in a prospective cohort of US women. Cancer Causes Control 2002; 13: 325-32.

28. Daling JR, Melane KE, Doody DR, et al. Relation of body mass index to tumor markers and survival among young women with invasive ductal breast carcinoma. Cancer 2001; 92: 720-9.

29. Goodwin PJ, Ennis M, Bahl M, et al. High insulin levels in newly diagnosed breast cancer patients reflect underlying insulin resistance and are associated with components of the insulin resistance syndrome. Breast Cancer Res Treat 2009; 114: 517-25.

30. Irving BA, Davis CK, Brock DW, et al. Effect of exercise training intensity on abdominal visceral fat and body composition. Med Sci Sports Exerc 2008; 40: 1863-72.

31. Slentz CA, Aiken LB, Houmard JA, et al. Inactivity, exercise, and visceral fat. STRRIDE: a randomized, controlled study of exercise intensity and amount. J Appl Physiol 2005; 99: 1613-8.

32. Ohkawara K, Tanaka S, Miyachi M, et al. A dose-response relation between aerobic exercise and visceral fat reduction: systematic review of clinical trials. Int J Obes (Lond) 2007; 31: 1786-97.

33. Velthuis MJ, Schuit AJ, Peeters PH, Monninkhof EM. Exercise program affects body composition but not weight in postmenopausal women. Menopause 2009; 16: 777-84.

34. De Lorenzo A, Nartinoli R, Yaia F, Di Renzo L. Normal weight obese (NWO) women: an evaluation of candidate new syndrome. Nutr Metab Cardiovasc Dis 2006; 16: 513-23.

\section{Address for correspondence}

Katarzyna Hojan MD, PhD

Department of Rehabilitation

Greater Poland Cancer Center

Garbary 15

61-866 Poznan

phone number +48 618850705

e-mail: khojan@op.pl 